\title{
RESPOSTA DA IRRIGAÇÃO E DA APLICAÇÃO DE FUNGICIDAS SOBRE A QUALIDADE SANITÁRIA E PRODUTIVIDADE DE GRÃOS DE MILHO
}

José Roberto Chaves Neto, Ricardo Boscaini, Renato Carnellosso Guerra, Nívea Raquel Ledur, Maurivan Travessini, Mayara Torres Mendonça, Ivan Francisco Dressler da Costa

Universidade Federal de Santa Maria - UFSM. E-mail: jose.chavesneto@gmail.com

\section{RESUMO}

Objetivou-se com o estudo avaliar a resposta da irrigação e da aplicação foliar de fungicida sobre o complexo grãos ardidos, a incidência de fungos (teste de sanidade - Blotter test) e produtividade de grãos de dois híbridos de milho. Os experimentos foram conduzidos na safra agrícola 2014/15, em Cruz Alta, RS. Para ambos os experimentos o delineamento utilizado foi em blocos casualizados e os tratamentos arranjados em esquema fatorial: 2 (híbridos comerciais) x 4 (3 fungicidas e 1 testemunha), com 4 repetições. Em laboratório, os grãos foram avaliados, quanto à porcentagem de grãos ardidos, sanidade de grãos pelo método de "Blotter test", peso de mil grãos e produtividade de grãos. Houve influência do uso da irrigação, do híbrido, e da aplicação de fungicidas sobre a produtividade de grãos e a incidência de grãos ardidos e fungos fitopatogênicos. A irrigação favoreceu uma maior incidência de grãos ardidos e dos fungos Fusarium sp. e Aspergillus sp. O híbrido BG7060HR proporcionou uma menor incidência de fungos e de grãos ardidos, paralelamente a uma maior massa de mil grãos e produtividade quando aplicou-se o fungicida Azoxistrobina + Benzovindiflupir. A aplicação de fungicidas no estádio V8 da cultura reduziu a incidência dos fungos Fusarium sp. e Aspergillus sp., destacando-se o fungicida Azoxistrobina + Benzovindiflupir.

Palavras-chave: controle químico; incidência de fungos; grãos ardidos; Zea mays L.

\section{RESPONSE OF IRRIGATION AND APPLICATION OF FUNGICIDES ON THE PRODUCTIVITY AND SANITARY QUALITY OF GRAINS OF TWO CORN HYBRIDS}

\begin{abstract}
The objective of this study was to evaluate the response of irrigation and foliar application of fungicide on the burned grain complex, fungal incidence (Blotter test) and grain yield of two maize hybrids. The experiments were conducted in the agricultural crop 2014/15, in Cruz Alta, RS. For both experiments, the treatments were arranged in a randomized block design and arranged in factorial scheme: 2 (commercial hybrids) $x 4$ ( 3 fungicides and 1 control), with 4 replicates. In the laboratory, the grains were evaluated, as percentage of burned grains, grain sanity by Blotter test method, weight of one thousand grains and grain yield. There was influence of the use of irrigation, the hybrid, and the application of fungicides on grain yield and the incidence of burned grains and phytopathogenic fungi. Irrigation favored a higher incidence of burned grains and fungi Fusarium sp. and Aspergillus sp. The hybrid BG7060HR provided a lower incidence of fungi and burned grains, parallel to a greater mass of a thousand grains and productivity when the fungicide Azoxystrobin + Benzovindiflupir was applied. The application of fungicides in the V8 stage of the culture reduced the incidence of fungi Fusarium sp. and Aspergillus sp., especially the fungicide Azoxystrobin + Benzovindiflupir.
\end{abstract}

Keywords: chemical control; incidence of fungal; rot grains; Zea mays L.

\section{INTRODUÇÃO}

Nos últimos anos, a ocorrência de doenças na cultura do milho (Zea mays L.) tornou-se cada vez mais intensa, gerando não só redução do potencial produtivo, mas também perdas relacionadas a qualidade dos grãos. Dentre estas, a principal doença é a podridão de espigas e grãos, sendo o complexo de grãos 
ardidos, um dos principais danos à cultura que resulta na descoloração dos grãos, redução nos conteúdos de carboidratos, proteínas e açúcares totais, em virtude do desenvolvimento de fungos presentes no campo, como o Fusarium verticilioides, Fusarium. graminearum, Stenocarpella maydis, S. macrospora, e fungos de armazenamento como Penicciliium sp. e Aspergillus sp (MENDES et al., 2012; RIZZARDI et al., 2017). Alguns destes fungos, quando em contato com os grãos, além de ocasionarem a redução da massa e da qualidade fitossanitária, em condições ambientais ideais, podem biosintetizar substâncias tóxicas denominadas micotoxinas, altamente perigosas aos animais e seres humanos (MENDES et al., 2011; MENDES et al., 2012).

Existe uma preocupação dos órgãos fiscalizadores em relação ao conteúdo de grãos ardidos e a presença de micotoxinas em milho, em função do destino dos grãos produzidos, visto que cerca de $70 \%$ dos mesmos, produzidos no Brasil e mundo, são destinados para a alimentação animal, podendo causar intoxicação e até mesmo a morte de animais. Na cultura do milho, a tolerância máxima de grãos ardidos pela legislação brasileira para comercialização dos lotes é de $6 \%$, enquanto o mercado internacional tem como limite máximo permitido para a comercialização apenas 2\% (BRASIL, 2009; LANZA et al., 2016; RIZZARDI et al., 2017).

Em todo o Brasil o aumento na incidência e severidade das doenças na cultura do milho, está relacionado ao estreitamento das relações patógeno-hospedeiro-ambiente. Diversos fatores ocasionam este estreitamento, como por exemplo: o aumento da irrigação nos campos de produção de milho, ausência de rotação de culturas, adensamento de plantas, plantio direto, utilização de híbridos suscetíveis, ampliação das épocas de cultivo (1a e 2a safra), fatores que associados permitem o aumento da sobrevivência dos fitopatógenos no campo (MENDES et al., 2011; SABATO et al., 2013). $\mathrm{Na}$ região sul do país existe um agravante para o desenvolvimento de fungos associados aos grãos, que são as condições ambientais favoráveis (tempo, temperatura e substrato), como chuvas cumulativas durante as fases de polinização e formação dos grãos o gera incremento de grãos avariados e fungos associados aos grãos (RIZZARDI et al., 2017).

$\mathrm{O}$ aumento das áreas plantadas de milho com o uso inadequado da irrigação, permitindo um excesso de água na lavoura, favorece o desenvolvimento do patógeno e pode acelerar sua taxa de crescimento (COSTA; COTA, 2009). Costa et al. (2015), destacam que a pratica de cultivar híbridos com diferentes níveis de resistência aos fungos causadores de podridões de espigas e grãos é um fato que vem gerando um aumento na perda de produtividade a cada safra.

Para o controle de doenças foliares e de grãos na cultura do milho recomenda-se a utilização de aplicação de fungicidas, rotação de cultura, tratamento de sementes, redução da densidade de plantas, adubação equilibrada, principalmente com potássio e nitrogênio (ALVES et al., 2012; BRITO et al., 2012; BARBOSA, 2010). Além destes métodos o uso de híbridos com resistência genética aos fungos fitopatogênicos é considerado como o método mais eficiente e econômico quando comparado aos outros (MUNHOZ et al., 2015). No entanto, quando aliado a práticas como o uso adequado da irrigação, controle químico (fungicidas) com dose recomendada e na época correta, tende a fornece maior sanidade a cultura (GONÇALVES et al., 2012; MANERBA et al., 2013; KLUGE et al., 2017).

Chaves Neto et al. (2017), ao avaliarem a eficácia da aplicação foliar de diferentes fungicidas na dose recomendada no estádio fenológico V8, para o controle da mancha branca em plantas de milho, obtiveram como resultado eficácia superior a $90 \%$ no controle em condições de campo, para os fungicidas Epoxiconazol + Piraclostrobina, com um dos princípios ativos do grupo das estrobilurinas. Stefanello et al. (2012), ao avaliarem a influência da aplicação do fungicida Azoxistrobina + Ciproconazol via foliar quanto a presença de fungos, em grãos colhidos de milho, constataram que a pulverização com fungicida Azoxistrobina + Ciproconazol não resultou em menor incidência do fungo Penicillium sp. nos grãos.

De acordo com Costa et al. (2015) e Mendes et al. (2012), torna-se fundamental avaliar a presença de híbridos com níveis de resistência constante, e, a diagnose e identificação, em laboratório, de fungos presentes nos grãos vindos diretamente do campo ou durante o período de armazenamento. O teste de sanidade (método de Blotter test) é uma alternativa prática e viável para avaliar o efeito dos diferentes níveis de resistência dos híbridos e das práticas culturais ao longo do ciclo 
da cultura, sobre a incidência de fungos causadores de podridões de espigas e grãos (COSTA et al., 2015; PILETTI et al., 2014).

Recomenda-se além do uso adequado da irrigação, a utilização de genótipos resistentes para o controle de doenças foliares e de espiga na cultura do milho (SABATO et al., 2013). Porém informações sobre a influência da irrigação e sobre o uso de híbridos de diferentes níveis de resistência de milho disponíveis para cultivo frente aos fungos responsáveis pelas podridões da espiga e grãos são escassas (PILETTI et al., 2014; COSTA et al., 2015). Sendo assim, objetivou-se como o trabalho avaliar a resposta da irrigação e da aplicação foliar de fungicida sobre o complexo grãos ardidos, a incidência de fungos (teste de sanidade - Blotter test) e produtividade de grãos de dois híbridos de milho.

\section{MATERIAL E MÉTODOS}

Foram conduzidos dois experimentos, na safra agrícola de 2014/2015, na área experimental da Cooperativa Central Gaúcha Ltda (CCGL), localizada no município de Cruz Alta, região centro-norte do estado de Rio Grande do Sul, cujas coordenadas são $28^{\circ}$ 51' 49" de latitude e 53 31' 40" de longitude, e uma altitude de 452 metros. O clima da região, é do tipo Cfa definido como úmido em todas as estações do ano, verão quente e moderadamente quente (Köppen, 1948), com pluviosidade média anual de $875 \mathrm{~mm}$ e uma temperatura média de $16,9{ }^{\circ} \mathrm{C}$. O solo é classificado como Latossolo Vermelho Distrófico típico (EMBRAPA, 2013b).

O primeiro experimento (ambiente 1) foi conduzido na presença de irrigação por aspersão em pivô central fixo, onde as irrigações foram executadas em um turno de rega fixo de cinco dias, com aplicação da lâmina de irrigação a 100\% da evapotranspiração da cultura. O segundo experimento (ambiente 2) foi conduzido na ausência de irrigação. Ambos os experimentos foram semeados, com auxílio de uma semeadoraadubadora de quatro linhas, em 17/09/2014, as áreas foram preparadas para o sistema de semeadura convencional, onde o preparo do solo constituiu-se de uma gradagem média e outra leve, na véspera da implantação dos experimentos.

O delineamento experimental utilizado foi em blocos casualizados (DBC), com quatro repetições, em esquema fatorial $2 \times 4$, totalizando 8 tratamentos e 32 unidades experimentais. Estas eram formadas por quatro fileiras de $10,0 \mathrm{~m}$, com espaçamento de0,50 $\mathrm{m}$ entre fileiras, onde cada parcela possuía uma área total de $20 \mathrm{~m}^{2}$, com um estande final de 65.000 plantas ha ${ }^{-1}$ em cada ambiente (irrigado e não irrigado). O primeiro fator era composto por dois híbridos, diferenciados de acordo com o nível de tolerância a fungos causadores da podridão de espiga e grãos: suscetível (BG7051H) e moderadamente resistente (BG7060HR) (CRUZ et al., 2013). O segundo fator consistiu na aplicação foliar de três fungicidas: Epoxiconazol + Piraclostrobina, na dose $380 \mathrm{~mL} \mathrm{ha}^{-1}$; Ciproconazol + Picoxistrobina, na dose $300 \mathrm{~mL} \mathrm{ha}^{-1}$ e Azoxistrobina + Benzovindiflupir, na dose $150 \mathrm{~g} \mathrm{ha}^{-1} \mathrm{e}$, um controle (sem aplicação).

A adubação de base para ambos os experimentos foi realizada com aplicação de 300 $\mathrm{kg} \mathrm{ha}^{-1}$ do formulado de $\mathrm{N}, \mathrm{P}_{2} \mathrm{O}_{5}$ e $\mathrm{K}_{2} \mathrm{O}$ (09-26-14). Para a adubação de cobertura foi aplicado sulfato de amônio em ambos os experimentos $(300 \mathrm{~kg}$ $h^{-1}{ }^{-1}$, aos 35 dias após a emergência. O tratamento de sementes, o controle de pragas e plantas daninhas foram realizados conforme recomendações propostas para a cultura na região (EMBRAPA, 2013b).

As aplicações foliares dos fungicidas foram realizadas no estágio fenológico V8 (oito folhas completamente desenvolvidas), com o auxílio de um pulverizador costal/manual, pressurizado com $\mathrm{CO}_{2}$, com barra de quatro bicos do tipo leque (RX 11002 / TEEJET), espaçados $0,50 \mathrm{~m}$, atingindo faixa de aplicação de $2,0 \mathrm{~m}$, à uma pressão de trabalho de 40 libras.pol $^{-2}$ e uma velocidade de caminhamento de $1 \mathrm{~m} \cdot \mathrm{s}^{-1}$.

A colheita das espigas foi realizada manualmente na área útil de cada unidade experimental (duas linhas centrais com oito metros de comprimento). Em seguida foi realizada a debulha e pesagens dos grãos, estimando-se a produtividade $\left(\mathrm{kg} \mathrm{ha}^{-1}\right)$, sendo corrigida para $13 \%$ de umidade. $O$ peso de 1000 grãos (g) foi obtido pela pesagem de quatro subamostras de mil grãos de cada unidade experimental, sendo os dados corrigidos para $13 \%$ de umidade.

Em seguida, os grãos de cada unidade experimental foram homogeneizados para posterior retirada de uma amostra representativa de $250 \mathrm{~g}$ de cada tratamento e híbrido para cada ambiente. As avaliações de porcentagem de grãos ardidos e sanidade de grãos foram realizadas na Clínica Fitossanitária, do departamento de Defesa Fitossanitária, do 
Centro de Ciências Agrárias da Universidade Federal de Santa Maria.

A incidência de grãos ardidos (\%), foi determinada com base na avaliação das amostras compostas $(250 \mathrm{~g})$, seguindo procedimento proposto pela portaria no 11, de 12/04/96 (BRASIL, 1996), que consiste na separação visual e na determinação da porcentagem de grãos que apresentavam um quarto de descoloração.

Para a avaliação de GA coletaram-se de forma aleatória $250 \mathrm{~g}$ de grãos de cada parcela, separando-se visualmente e pesando aqueles com perda de coloração superior a 25\% (BRASIL, 1996).

O teste de sanidade foi realizado pelo método de papel filtro com congelamento (Blotter test). Foram utilizados 200 grãos de cada amostra composta, em oito repetições de 25 grãos, distribuídos no interior de caixas plásticas, tipo gerbox, previamente limpas com álcool etílico $70 \%$, contendo uma camada de três folhas de papel filtro autoclavadas e umedecidas com água destilada, e incubadas durante 24 horas, à temperatura de $25 \pm 2^{\circ} \mathrm{C}$. Após este período, as placas foram transferidas para ambiente a -20 으, durante 24 horas, e, posteriormente, para câmara de crescimento sob iluminação contínua, à temperatura de $25 \pm 2^{\circ} \mathrm{C}$, por um período de nove dias. Após nove dias de incubação com o auxílio de lupa estereoscópica e microscópio, os fungos foram identificados por meio das características morfológicas de suas estruturas. Os resultados foram expressos em porcentagem de grãos contaminados, para cada fungo identificado (BRASIL, 2009).

A avaliação de eficácia de cada fungicida foi realizada com base na fórmula descrita por ABBOTT (1925):

Onde:

$$
\mathrm{E} \%=\frac{\mathrm{T}-\mathrm{F}}{T} \times 100
$$

$\mathrm{T}=$ Incidência média na testemunha;

$\mathrm{F}=$ Incidência média nos tratamentos;

$\mathrm{E} \%$ = Percentual de eficácia de cada tratamento avaliado.

Todos os dados coletados foram submetidos ao teste de normalidade e homogeneidade dos erros, e posteriormente ao teste $\mathrm{F}$ da análise de variância (ANOVA). As médias foram comparadas pelo teste Tukey, adotando-se o nível de $5 \%$ de probabilidade de erro $(p<0,05)$. Foi utilizado o programa estatístico Sisvar versão 5.6 (FERREIRA, 2014) para as análises.

\section{RESULTADOS E DISCUSSÃO}

$\mathrm{Na}$ Tabela 1, encontra-se o resumo da análise de variância e os valores médios da porcentagem de grãos ardidos, incidência e percentual de controle dos fungos Fusarium sp. e Aspergillus sp, massa de mil grãos e produtividade de grãos de milho, envolvendo dois ambientes (com e sem irrigação).

A porcentagem de grão ardidos sofreu influência de todos os fatores estudados, assim como da interação tripla 'irrigação $\mathrm{x}$ híbrido $\mathrm{x}$ tratamento', indicando que o comportamento dos híbridos apresentou respostas diferenciadas quanto submetidos a presença ou ausência da irrigação e a aplicação foliar de fungicidas (Tabela 1).

A porcentagem de grão ardidos sofreu influência de todos os fatores estudados, assim como da interação tripla 'irrigação $\mathrm{x}$ híbrido $\mathrm{x}$ tratamento', indicando que o comportamento dos híbridos apresentou respostas diferenciadas quanto submetidos a presença ou ausência da irrigação e a aplicação foliar de fungicidas (Tabela 1). Verificou-se maior incidência de grãos ardidos $(13,1 \%)$ no ambiente irrigado, provavelmente devido ao fato de que a água disponível no meio tornou o ambiente mais propício ao desenvolvimento dos fungos causadores do complexo grãos ardidos, o que pode ter acelerado seu desenvolvimento e elevado sua taxa de crescimento. Porcentagem de grãos ardidos semelhante às descritas neste trabalho, foram observadas por Chaves Neto et al. (2018a), ao avaliarem a qualidade sanitária de grãos e produtividade de dois híbridos de milho cultivados na região do central do Rio Grande do Sul, cultivados em diferentes sistemas de semeadura e submetidos a aplicação foliar de fungicida, apresentaram medias de porcentagem de grãos ardidos variando de 10,28 a $12,50 \%$.

Quanto ao fator híbrido, a maior incidência de grãos ardidos foi para o híbrido BG7051H, considerado susceptível, ao passo que - BG7060HR apresentou porcentagem de grãos ardidos significativamente inferior, sendo considerado resistente (Tabela 1), confirmando as informações publicadas pela empresa produtora das sementes desses híbridos BioGene, que os classifica como suscetível e moderadamente resistente, respectivamente. Duarte et al. (2009) e Mendes et al. (2012), também verificaram diferença quanto à resistência e/ou susceptibilidade aos fungos causadores do complexo grãos ardidos por parte 
de diferentes híbridos sob aplicação foliar de fungicida e com inoculação dos fungos $F$. verticilioides, $S$. maydis e $S$. macrospora, em dois sistemas de cultivo, respectivamente. Piletti et al. (2014) e Silva et al. (2014), destacam que uma ferramenta importante para o controle de doenças em regiões com epidemias frequentes é o conhecimento do nível de resistência dos híbridos aos patógenos.

Houve redução na incidência de grãos ardidos em função da aplicação de fungicidas via foliar (Tabela 1). O fungicida Elatus resultou na menor incidência de grãos ardidos, com 3,84 \%, valor inferior ao máximo tolerado pela legislação brasileira que é de 6\% (BRASIL, 2009). O tratamento testemunha foi o que obteve maior porcentagem de grãos ardidos, com 20,66 \%, diferindo dos demais tratamentos (Tabela 1).

Os valores de grãos ardidos no tratamento testemunha, alerta para cuidados a serem adotados quanto à utilização desses grãos na alimentação de animais ou mesmo para seres humanos. Entretanto, o fato de ter havido uma alta porcentagem de grãos ardidos, não implica necessariamente na presença de altos teores de micotoxina nos grãos produzidos, visto que os fungos causadores do complexo de grãos ardidos necessitam de condições ambientais especificas para biosintetizar estas toxinas, como por exemplo, alternância de temperatura diurna e noturna (STUMPF et al., 2013).

Estes dados são semelhantes ao relatados por Duarte et al. (2009) e Chaves Neto et al. (2018b), verificaram que a aplicação de fungicidas no estádio fenológico de prépendoamento e V8 $(80 \mathrm{~cm}$ de altura), respectivamente, proporcionou redução na incidência de grãos ardidos, sendo que os fungicidas que proporcionaram a menor incidência foram Piraclostrobina + Epoxiconazole e Azoxistrobina + Benzovindiflupir, respectivamente. Chaves Neto et al. (2017) e Juliatti et al. (2014), ao avaliarem a eficácia da aplicação via foliar de diferentes fungicidas a campo para o controle da mancha branca do milho, destacaram a eficácia em reduzir a incidência da doença devido ao uso de fungicidas do grupo das estrobirulinas em mistura com triazóis.

No teste de sanidade de grãos foram detectados e identificados os fungos Fusarium sp. e Aspergillus sp. (Tabela 1). De acordo com Stefanello et al. (2012) e Lanza et al., (2016), os gêneros de fungos mais frequentemente detectados e associados aos grãos de milho recém-colhido foram Fusarium sp., seguido por Aspergillus sp. e Penicillium sp. Mendes et al. (2012), relatam que as espécies mais frequentemente detectadas em grãos de milho são Fusarium moniliforme, Fusarium verticillioides, Aspergillus flavus e Stenocarpella maydis, que além de causarem o dano complexo "grãos ardidos" podem biosintetizar micotoxinas.

Para a incidência do fungo Fusarium sp. e Aspergillus sp. constatou-se diferença significativa $(p \leq 0,05)$, para os fatores irrigação e tratamento, e para todas as interações duplas entre os fatores estudados, assim como para interação tripla 'irrigação $x$ híbrido $x$ tratamento' (Tabela 1). Quanto ao fator irrigação, de maneira geral, os valores médios de incidência dos fungos Fusarium sp. e Aspergillus sp., foram maiores no experimento com irrigação (Tabela 1). A baixa incidência do fungo Aspergillus $\mathrm{sp}$. no experimento sem irrigação (4,94 \%) (Tabela 1), pode estar relacionada ao nível de resistência dos híbridos cultivados ou as condições climáticas durante o ciclo da cultura (COSTA et al., 2012; STEFANELLO et al., 2012).

Os resultados obtidos neste trabalho corroboram com os relatados por Rizzardi et al. (2017), que verificaram maior incidência dos fungos causadores do complexo de grãos ardidos em quatro híbridos de milho (DKB245, DKB390Y, P30F53H e P30R50H), na safra agrícola 2010/11, nos meses de dezembro e janeiro, período em que os índices pluviométricos foram superiores, mostrando que a maior disponibilidade de água no campo, contribui para o maior desenvolvimento do fungo Stenocarpella maydis.

Quanto ao fator tratamento observou-se que, para a incidência de fungo Fusarium sp. o tratamento Elatus ${ }^{\circ}$ foi significativamente superior $(p \leq 0,05)$ aos demais, por proporcionar maior eficácia no controle e menor incidência deste fungo, com médias de controle de 60,81\% e incidência de 32,63\% (Tabela 1). Para o fungo Aspergillus sp., os tratamentos Abacus $\mathrm{HC}^{\circ}$, Aproach Prima e Elatus apresentaram eficácia no controle $(p \leq 0,05)$ superior em relação a testemunha, com médias de 68,94; 62,13 e 69,79\% (Tabela 1), evidenciando a alta eficácia dos fungicidas pertencentes aos grupos químicos estrobilurinas em mistura com triazóis. Resultados semelhantes foram encontrados por Duarte et al. (2009) e Stefanello et al. (2012), que apontam a eficiência de fungicidas do grupo das estrobilurinas, em mistura com triazóis, na 
redução da incidência de fungos associados a grãos de milho.

Para a massa de 1000 grãos houve significância $(p \leq 0,05)$ para os fatores híbrido e tratamento, assim como a interação irrigação $x$ tratamento (Tabela 1). Quanto ao fator híbrido, o híbrido BG7060HR apresentou a maior massa de mil grãos, com 477,50 g, diferindo estatisticamente do híbrido BG7051H. Já quanto ao fator tratamento contatou-se que, a aplicação foliar do fungicida Elatus proporcionou maior massa de mil grãos, com média de 559,13 g, e os demais tratamentos não diferiram ente si, com médias variando de 397,02 a 423,73 g.
Para a produtividade de grãos observouse diferença significativa $(p \leq 0,05)$ para os fatores irrigação e tratamento e para a interação irrigação x híbridos, evidenciando a dependência destes dois fatores (Tabela 1). 0 ambiente irrigado foi estatisticamente superior ao não irrigado, proporcionando a maior produtividade com média de 5,20351 Mg ha ${ }^{-1}$. Quanto ao fator tratamento, constatou-se que o fungicida Elatus ${ }^{\circ}$, proporcionou a maior produtividade, com média $5,79257 \mathrm{Mg} \mathrm{ha}^{-1}$, sendo os demais tratamentos estatisticamente semelhantes entre si (Tabela 1 ).

Tabela 1. Resumo da análise de variância e valores médios de grãos ardidos (GA - \%), porcentagem de incidência e percentual de eficácia dos tratamentos no controle dos fungos Fusarium sp. e Aspergillus sp., massa de 1000 grãos (MMG - g) produtividade (PROD - $\mathrm{Mg} \mathrm{ha}^{-1}$ ) de grãos de milho, envolvendo dois ambientes (com e sem irrigação)

\begin{tabular}{|c|c|c|c|c|c|c|c|}
\hline \multirow[b]{2}{*}{ Tratamentos } & \multirow[b]{2}{*}{ Grãos ardidos (\%) } & \multicolumn{4}{|c|}{ Sanidade de Grãos } & \multirow[b]{2}{*}{$\begin{array}{c}\text { MMG } \\
\text { (g) }\end{array}$} & \multirow{2}{*}{$\begin{array}{c}\text { PROD } \\
\left(\mathrm{Mg} \mathrm{ha}^{-1}\right)\end{array}$} \\
\hline & & Fusariur & sp. (\%) & $\begin{array}{r}\text { Aspergi } \\
\text { (\% }\end{array}$ & $\begin{array}{l}\text { illus sp. } \\
\text { 6) }\end{array}$ & & \\
\hline $\mathrm{F}^{1}$ & \multicolumn{7}{|c|}{ Quadrado Médio (QM) } \\
\hline Irrigação (I) & $576,53^{*}$ & \multicolumn{2}{|c|}{$8646,13^{*}$} & \multicolumn{2}{|c|}{$12012,50 *$} & $5271,39^{\mathrm{ND}}$ & $37923565,80 *$ \\
\hline Híbrido $(\mathrm{H})$ & $67,36^{*}$ & \multicolumn{2}{|c|}{$190,13^{\mathrm{ND}}$} & \multicolumn{2}{|c|}{$24,50^{\mathrm{ND}}$} & $623854,28 *$ & $1261356,42^{\mathrm{ND}}$ \\
\hline Tratamento $(\mathrm{T})$ & $682,46^{*}$ & \multicolumn{2}{|c|}{$14615,46^{*}$} & \multicolumn{2}{|c|}{$3126,67^{*}$} & $925623,59 *$ & $14044276,23 *$ \\
\hline$I^{*} \mathrm{H}$ & $2,32^{\mathrm{ND}}$ & \multicolumn{2}{|c|}{$2926,12^{*}$} & \multicolumn{2}{|c|}{$578,00 *$} & $52803,48^{\mathrm{ND}}$ & $11316218,47^{*}$ \\
\hline I*T & $296,80 *$ & \multicolumn{2}{|c|}{$1253,79 *$} & \multicolumn{2}{|c|}{$287,17^{*}$} & $130349,10 *$ & $175156,66^{\mathrm{NS}}$ \\
\hline $\mathrm{H}^{*} \mathrm{~T}$ & $40,33 *$ & \multicolumn{2}{|c|}{$3938,46^{*}$} & \multicolumn{2}{|c|}{$461,83^{*}$} & $56787,14^{\mathrm{ND}}$ & $120639,49^{\text {NS }}$ \\
\hline $\mathrm{I}^{*} \mathrm{H}^{*} \mathrm{~T}$ & $18,40^{*}$ & \multicolumn{2}{|c|}{$931,79 *$} & \multicolumn{2}{|c|}{$641,33 *$} & $33334,92^{\mathrm{ND}}$ & $517927,74^{\mathrm{NS}}$ \\
\hline Erro & 5,05 & \multicolumn{2}{|c|}{167,52} & \multicolumn{2}{|c|}{69,07} & 42133,34 & 453762,43 \\
\hline CV (\%) & 23,32 & \multicolumn{2}{|c|}{22,74} & \multicolumn{2}{|c|}{56,83} & 45,99 & 15,19 \\
\hline \multicolumn{8}{|c|}{ Sistema de Irrigação } \\
\hline Com Irrigação & $13,10 \mathrm{~b}$ & \multicolumn{2}{|c|}{$65,13 b$} & \multicolumn{2}{|c|}{$24,31 b$} & $449,15 a$ & $5,20351 a$ \\
\hline Sem Irrigação & $6,19 \underline{a}$ & \multicolumn{2}{|c|}{$48,68 a$} & \multicolumn{2}{|c|}{$4,94 a$} & $443,41 a$ & $3,66396 b$ \\
\hline \multicolumn{8}{|c|}{ Híbrido } \\
\hline BG7051H & $10,83 b$ & \multicolumn{2}{|c|}{$58,13 a$} & \multicolumn{2}{|c|}{$14,19 a$} & $415,06 b$ & $4,29335 a$ \\
\hline BG7060HR & $8,46 \underline{a}$ & \multicolumn{2}{|c|}{$55,69 a$} & \multicolumn{2}{|c|}{$15,06 a$} & $477,50 a$ & $4,57412 a$ \\
\hline Trat & nento & & Efc. $(\%)^{3}$ & & Efc.(\%) & & \\
\hline Testemunha & $20,66 c$ & $83,25 d$ & 0,00 & $29,38 b$ & 0,00 & $397,02 b$ & $3,66123 b$ \\
\hline Abacus $\mathrm{HC}^{\circ}$ & $6,08 a b$ & $62,38 c$ & 25,08 & $9,13 a$ & 68,94 & $405,22 b$ & $4,23602 b$ \\
\hline Aproach Prima ${ }^{\circ}$ & $7,98 b$ & $49,38 b$ & 40,69 & $11,13 a$ & 62,13 & $423,73 b$ & $4,04512 b$ \\
\hline Elatus $^{\circ}$ & $3,84 \underline{a}$ & $32,63 a$ & 60,81 & $8,88 a$ & 69,79 & $559,13 a$ & $5,79257 a$ \\
\hline
\end{tabular}

Médias seguidas de mesma letra na coluna não diferem estatisticamente entre si pelo Teste de Tukey, em nível de significância de $5 \%$. ${ }^{(1)}$ Teste $F,{ }^{(2)}$ Quadrado médio, * significativo a 5\%, (NS) não significativo e ${ }^{(3)}$ Eficácia dos tratamentos.

Estes valores de produtividade estão de acordo com as médias do Estado do Rio Grande do Sul, que são inferiores a $6,56 \mathrm{Mg} \mathrm{ha}^{-1}$ para a mesma safra agrícola 2014/15 (Companhia
Nacional de Abastecimento, CONAB, 2015). Vilela et al. (2012), relataram que a aplicação de fungicida na cultura do milho tem propiciado ganhos de produtividade. 
Resultados semelhantes foram observados por Brito et al. (2012), que ao avaliarem o efeito da aplicação de fungicidas no controle de doenças foliares do milho e na produtividade de grãos, observaram que a aplicação foliar do fungicida Azoxystrobin + Ciproconazole, no pré-pendoamento possibilitou um incremento na produtividade de grãos em torno de $12 \%$. Lanza et al. (2016), avaliando a eficácia da aplicação foliar de fungicidas na redução de patógenos e incremento de produtividade de grãos de milho, constataram que a aplicação foliar de fungicidas promoveu uma maior produtividade de grãos em comparação com a testemunha. Por outro lado, há relatos de ausência ou baixa influência da aplicação de fungicidas no incremento da produtividade de grãos na cultura do milho. Ecco et al. (2014), relatam que a aplicação do fungicida piraclostrobina (133 $\left.\mathrm{g} \mathrm{L}^{-1}\right)+$ epoxiconazol $\left(50 \mathrm{~g} \mathrm{~L}^{-}\right.$ $\left.{ }^{1}\right)$ no estádio de pré-pendoamento sobre dois híbridos de milho ( 30F53HX e P3161HX) não interferiu em nenhuma das características agronômicas, dentre elas a produtividade de grãos.

A significância da interação tripla 'irrigação $\mathrm{x}$ híbrido $\mathrm{x}$ tratamento', para $\mathrm{a}$ porcentagem de grãos ardidos (Tabela 2), permite inferir que há diferenças na resposta dos híbridos avaliados quanto à aplicação foliar dos fungicidas Abacus $\mathrm{HC}^{\circ}$, Aproach Prima e Elatus ${ }^{\circ} \mathrm{e}$ que isso é dependente do uso da irrigação.

Para o híbrido BG7051H, na presença da irrigação, o tratamento testemunha apresentou porcentagem de grãos ardidos estatisticamente superior $(p \leq 0,05)$ em relação aos tratamentos com aplicação de fungicidas (Abacus $\mathrm{HC}^{\circ}$, Aproach Prima e Elatus ${ }^{\circ}$ ), os quais não diferiram entre si, apresentando as menores porcentagens de grãos ardidos (Tabela 2), o que permite inferir a eficácia dos fungicidas formulados a partir da mistura de princípios ativos dos grupos químicos estrobilurinas e triazóis no controle de patógenos causadores do complexo grãos ardidos (BRITO et al., 2012). No híbrido BG7060HR, o tratamento Elatus apresentou menor porcentagem de grãos ardidos, com média de 3,66\%, diferindo estatisticamente dos demais tratamentos (Tabela 2).

Mesmo na ausência da irrigação, ainda é possível destacar a presença de interação significativa entre tratamentos dentro de cada híbrido. Observou-se que os tratamentos não apresentaram diferenças significativas para a porcentagem de grãos ardidos no BG7060HR. No entanto, para o híbrido $\mathrm{BG} 7051 \mathrm{H}$, os tratamentos Elatus ${ }^{\circ}$ e Aproach Prima ${ }^{\circ}$, com médias de 5,78 e $3,95 \%$ respectivamente, diferiram estatisticamente $(p \leq 0,05)$ dos demais tratamentos (Tabela 2). Os valores de grãos ardidos encontrados neste trabalho, estão abaixo do máximo de grãos ardidos tolerado pela legislação brasileira para grãos de milho que é de 6\% (BRASIL, 2009).

A eficácia da aplicação destes fungicidas via foliar, em reduzir a incidência de grãos ardidos na cultura do milho, também foi relata por Brito et al. (2012), que constataram redução da incidência de grãos ardidos, por meio de duas aplicações, uma no estádio de dez folhas totalmente expandidas e a outra no prépendoamento do fungicida Azoxistrobina + Ciproconazol na dosagem de 0,30 I ha-1 + 0,5\% do óleo mineral. Duarte et al. (2009), observaram que uso de Piraclostrobina + Epoxiconazole, resultou em menor incidência de grãos ardidos. A eficácia dos fungicidas do grupo das estrobilurinas também foram observadas in vitro. Lopes et al. (2015), ao avaliarem a sensibilidade de isolados de Colletotrichum gloeosporioides a fungicidas, constataram que o fungicida Trifloxistrobina + Tebuconazol, promoveu menor crescimento micelial. Chaves Neto et al. (2017), observaram eficácia superior a $90 \%$ dos fungicidas Epoxiconazol + Piraclostrobina, Ciproconazol + Picoxistrobina e Azoxistrobina + Benzovindiflupir para o controle de mancha branca do milho em condições de campo.

No entanto, os resultados encontrados neste trabalho contradizem os obtidos por Small et al. (2012) e Lanza et al. (2016), segundo esses autores, não houve redução na incidência de grãos ardidos em milho com a aplicação foliar de diferentes fungicidas do grupo das estrobilurinas, em mistura com triazóis, apesar das distintas condições meteorológicas e dos diferentes híbridos.

Para o desdobramento dos híbridos dentro dos tratamentos, observou-se que ambos os híbridos avaliados não apresentaram diferenças significativas para a porcentagem de grãos ardidos nos tratamentos Abacus $\mathrm{HC}^{\circ}$, Aproach Prima ${ }^{\circ}$ e Elatus ${ }^{\circ}$, quando irrigados (Tabela 2). Por outro lado, o tratamento testemunha apresentou porcentagem de grãos ardidos estatisticamente superior para o híbrido BG7051H (36,43\%) quando comparado ao híbrido BG7060HR (26,59\%) (Tabela 3). Uma possível 
explicação pode estar relacionada à resistência moderada do híbrido BG7060HR aos fungos causadores do complexo grãos ardidos.

Outras pesquisas também relatam 0 comportamento diferenciado dos híbridos com relação a porcentagem de grãos ardidos. Duarte et al. (2009), Mendes et al. (2012) e Rizzardi et al. (2017), ao avaliarem o comportamento de diferentes híbridos com diferentes níveis de resistência a inoculação artificial de fungos relacionados a doenças de grãos, verificaram diferença significativa entre os híbridos para a porcentagem de grãos ardidos e que esta diferença está diretamente relacionada aos níveis de resistências destes híbridos e às técnicas adotadas duram o ciclo da cultura, como aplicação de fungicidas e o uso da irrigação.

Piletti et al. (2014) destacam que o conhecimento do nível de resistência dos híbridos é uma ferramenta crucial para um programa de manejo de doenças da cultura do milho, de modo a permitir a indicação de híbridos adequados para regiões onde existem condições favoráveis e registros de frequentes epidemias da doença.

É importante enfatizar que, o híbrido considerado susceptível (BG7050H) ao complexo "grãos ardidos", foi o que apresentou a maior incidência dos fungos Penicillium sp. e Aspergillus sp. Estes resultados confirmam a diferença genética entre os híbridos estudados neste experimento, uma vez que, de acordo com as características agronômicas disponibilizadas pela empresa BioGene (2015) responsável pela produção de sementes destes híbridos, que classifica o híbrido BG7050H e o BG7060HR, como moderadamente resistente e suscetível, respectivamente, a doenças de grãos.

Tabela 2. Desdobramento da interação sistema de semeadura $x$ híbrido $x$ tratamento referente a porcentagem de grãos ardidos (GA - \%), em grãos de milho envolvendo dois ambientes (com e sem irrigação)

\begin{tabular}{|c|c|c|c|c|}
\hline \multirow{4}{*}{ Tratamentos } & \multicolumn{4}{|c|}{ Sistemas de Irrigação } \\
\hline & \multicolumn{2}{|c|}{ Com Irrigação } & \multicolumn{2}{|c|}{ Sem Irrigação } \\
\hline & \multicolumn{4}{|c|}{ Híbridos } \\
\hline & BG7051H & BG7060HR & BG7051H & BG7060HR \\
\hline Testemunha & $36,43 b B$ & $26,59 \mathrm{cA}$ & $12,50 \mathrm{bB}$ & $7,14 \mathrm{aA}$ \\
\hline Abacus $\mathrm{HC}^{\circ}$ & $5,89 a A$ & $7,78 \mathrm{bA}$ & $8,13 a b B$ & $2,51 \mathrm{aA}$ \\
\hline Aproach Prima ${ }^{\circ}$ & $9,31 \mathrm{aA}$ & $10,51 b A$ & $5,78 \mathrm{aA}$ & $6,34 \mathrm{aA}$ \\
\hline Elatus ${ }^{\circ}$ & $4,62 \mathrm{aA}$ & $3,66 \mathrm{aA}$ & $3,95 \mathrm{aA}$ & $3,13 \mathrm{aA}$ \\
\hline Média Geral & $14,06 \mathrm{~B}$ & $12,13 \mathrm{~A}$ & $7,59 B$ & $4,78 \mathrm{~A}$ \\
\hline
\end{tabular}

*Médias seguidas de mesmas letras, minúsculas na coluna e maiúsculas na linha, não diferem estatisticamente entre si pelo Teste de Tukey, em nível de significância de 5\%.

A significância da interação sistemas de irrigação $\mathrm{x}$ híbridos $\mathrm{x}$ tratamentos, para à incidência do fungo Fusarium sp., permite inferir que houve diferenças na reação dos híbridos avaliados quanto a aplicação foliar dos fungicidas Abacus $\mathrm{HC}^{\oplus}$, Aproach Prima ${ }^{\circ}$ e Elatus e que isso é influenciado pelo uso da irrigação (Tabela 3).

Considerando o desdobramento dos tratamentos no experimento com irrigação, contatou-se que houve diferença significativa $(p \leq 0,05)$ em ambos os híbridos avaliados. $O$ tratamento Elatus foi o que proporcionou menor incidência e o maior controle do fungo Fusarium sp., com média de $47,00 \%$, diferindo estatisticamente dos demais, para o híbrido BG7051H. No híbrido BG7060HR, os tratamentos Aproach Prima e Elatus ${ }^{\circ}$, apresentaram a menor incidência do fungo Fusarium sp., diferindo, estatisticamente, dos demais tratamentos avaliados (Tabela 3). No híbrido BG7051H, no experimento sem irrigação, os tratamentos diferiram significativamente $(p \leq 0,05)$ quanto a incidência do fungo Fusarium sp., os tratamentos Abacus $\mathrm{HC}^{\circ}$ e Elatus apresentaram a menor incidência do fungo Fusarium sp., com médias de 23,50 e 34,50\%, respectivamente (Tabela 3).

Estes resultados comprovam a eficácia dos fungicidas do grupo das estrobilurinas, em mistura com triazóis, na redução da incidência do fungo Fusarium sp. Resultados semelhantes também foram descritos por Duarte et al. (2009) e Brito et al. (2012), que verificaram redução significativa na incidência de Fusarium sp., em grãos de milho, quando submetidos à aplicação 
foliar do fungicida Azoxystrobina + Ciproconazol. O mesmo desempenho foi observado por Stefanello et al. (2012), os quais, avaliando o efeito da aplicação foliar do fungicida Azoxistrobina + Ciproconazol, na incidência de fungos em grãos de milho, verificaram que o fungicida Azoxistrobina + Ciproconazol reduziu a incidência do fungo Fusarium sp., nos grãos colhidos. Ao contrário destes autores Lanza et al. (2016), constataram que a aplicação foliar de fungicidas não reduziu a incidência de patógenos fúngicos associados a grãos de milho.

Juliatti et al. (2014) e Chaves Neto et al. (2016), avaliando a eficácia da aplicação de diferentes fungicidas no controle de doenças foliares da cultura do milho, que também estão associadas às podridões de espigas e a incidência de fungos nos grãos após a colheita, destacaram a eficácia da aplicação de fungicidas do grupo das estrobirulinas em reduzir a incidência de doenças foliares.
Para o desdobramento dos híbridos dentro dos tratamentos, observou-se que no experimento com irrigação, os híbridos não diferiram estatisticamente $(p \leq 0,05)$ quanto a incidência do fungo Fusarium sp., nos tratamentos Testemunha e Abacus $\mathrm{HC}^{\circ}$. Por outro lado, o híbrido BG7060HR apresentou a menor incidência do fungo Fusarium sp., nos tratamentos Elatus e Aproach Prima ${ }^{\circ}(32,50$ e $36,50 \%$, respectivamente) (Tabela 3), comparando-se com o híbrido BG7051H, comprovando a maior tolerância do híbrido BG7060HR aos fungos causadores do complexo grãos ardidos. No experimento sem irrigação, os híbridos diferiram para todos os tratamentos, o híbrido BG7051H, apresentou a menor incidência do fungo Fusarium sp. nos tratamentos Testemunha e Abacus $\mathrm{HC}^{\circ}$, já nos tratamentos Aproach Prima e Elatus a menor incidência do fungo Fusarium sp. foi observada no híbrido BG7060HR.

Tabela 3. Desdobramento da interação sistema de irrigação $x$ híbrido $x$ tratamento referente à incidência de fungos do gênero Fusarium sp. (\%), em grãos de milho envolvendo dois ambientes (com e sem irrigação)

\begin{tabular}{|c|c|c|c|c|}
\hline \multirow{4}{*}{ Tratamentos } & \multicolumn{4}{|c|}{ Sistemas de Irrigação } \\
\hline & \multicolumn{2}{|c|}{ Com Irrigação } & \multicolumn{2}{|c|}{ Com Irrigação } \\
\hline & \multicolumn{4}{|c|}{ Híbridos } \\
\hline & BG7051H & BG7060HR & BG7051H & BG7060HR \\
\hline Testemunha & $84,50 \mathrm{bA}$ & $90,50 \mathrm{bA}$ & $68,00 \mathrm{bA}$ & $90,00 \mathrm{~dB}$ \\
\hline Abacus $\mathrm{HC}^{\circ}$ & $82,50 \mathrm{bA}$ & $77,00 \mathrm{bA}$ & $23,50 \mathrm{aA}$ & $66,50 \mathrm{cB}$ \\
\hline Aproach Prima & $70,50 b B$ & $36,50 a A$ & $54,50 \mathrm{bB}$ & $36,00 \mathrm{bA}$ \\
\hline Elatus $^{\circ}$ & $47,00 \mathrm{aB}$ & $32,50 \mathrm{aA}$ & $34,50 \mathrm{aB}$ & $16,50 \mathrm{aA}$ \\
\hline Média Geral & $71,13 \mathrm{~B}$ & $59,13 \mathrm{~A}$ & $45,13 \mathrm{~A}$ & $52,25 B$ \\
\hline
\end{tabular}

*Médias seguidas de mesmas letras, minúsculas na coluna e maiúsculas na linha, não diferem estatisticamente entre si pelo Teste de Tukey, em nível de significância de 5\%.

O comportamento diferenciado de híbridos de milho a incidência de fungos relacionados ao complexo grãos ardidos também foi observado por Mendes et al. (2012), que constataram que os híbridos de milho possuem comportamento diferente para os fungos estudados. Resultados semelhantes também foram descritos por Piletti et al. (2014) e Rizzardi, et al. (2017), que observaram comportamento diferenciado de híbridos quanto ao Stenocarpella macrospora fungo, que é um dos agentes etiológicos do complexo grãos ardidos.

Com base na significância da interação sistemas de irrigação $\mathrm{x}$ híbridos $\mathrm{x}$ tratamentos, para a incidência do fungo Aspergillus sp., podese inferir que as plantas de milho se comportaram de forma diferente quando submetidas a aplicação de fungicidas via foliar e quanto ao uso da irrigação (Tabela 4). De modo geral, os híbridos BG7051H e BG7060HR não diferiram significativamente $(p \leq 0,05)$ para a incidência do fungo Aspergillus sp., no experimento sem irrigação. Por outro lado, o híbrido $\mathrm{BG} 7051 \mathrm{H}$ apresentou a menor incidência do fungo Aspergillus sp., para o experimento sem irrigação (21,75\%), comparando-se com o híbrido BG7060HR (Tabela 4).

Quanto ao desdobramento dos tratamentos dentro dos híbridos (Tabela 4), observou-se que tanto no híbrido $\mathrm{BG} 7051 \mathrm{H}$ e no BG7060HR, no experimento com irrigação, a incidência do fungo Aspergillus sp., no tratamento Testemunha superou os demais tratamentos. A menor incidência para o híbrido 
BG7051H foi observada quando aplicou-se o tratamento Abacus $\mathrm{HC}^{\circ}(6,00 \%)$, já para o híbrido BG7060HR foi quando aplicou-se o tratamento Elatus ${ }^{\circ}$, com média de $10,50 \%$ de incidência do fungo Aspergillus sp. Para ambos os híbridos, no experimento sem irrigação, o tratamento Testemunha apresentou incidência do fungo Aspergillus sp. estatisticamente superior $(p \leq 0,05)$ em relação aos tratamentos com aplicação de fungicidas, os quais foram iguais entre si, apresentando as menores incidências, com médias variando de 0 a 3,50\% (Tabela 4).

A baixa incidência do fungo Aspergillus sp., em grãos de milho encontrada neste trabalho, também foi relatada Chaves Neto et al. (2018a), ao avaliarem a influência do sistema de semeadura e da aplicação foliar de fungicida sobre a produtividade e qualidade sanitária de grãos de milho, observaram baixa incidência do fungo Aspergillus sp., com valores médios variando de 0,88 a $1,88 \%$, em ensaios realizados na região central do Estado do Rio Grande do Sul.

Analisando o desdobramento dos híbridos dentro dos tratamentos para a fungo Aspergillus sp. (Tabela 4), observou que no experimento sem irrigação, em todos os tratamentos os híbridos não diferiram estatisticamente $(p \leq 0,05)$ entre si. No experimento com irrigação, houve diferença estatística entre os híbridos estudados para os tratamentos Testemunha, Abacus $\mathrm{HC}^{\circ}$ e Elatus, apenas no tratamento Testemunha o híbrido BG7060HR, apresentou maior incidência do fungo, já o híbrido $B G 7051 \mathrm{H}$, foi estatisticamente superior nos tratamentos Abacus $\mathrm{HC}^{\circ}$ e Elatus, quando comparado com o híbrido BG7060HR, que apresentou a menor incidência.

Estes resultados evidenciam a diferença entre os híbridos avaliados, quanto aos níveis de resistência a fungos causadores do complexo grãos ardidos, o híbrido BG7060HR sob aplicação de fungicidas resultou em uma menor incidência do fungo Aspergillus sp., o que mostra a diferença dos híbridos também em relação a resposta a aplicação de fungicidas.

Resultados semelhantes foram observados por Lanza et al. (2016), que constataram diferença entre os híbridos e entre as épocas de semeadura quanto a incidência do fungo Aspergillus sp. em grãos de milho. Chaves Neto et al. (2016), avaliando a sensibilidade in vitro de fungos causadores do complexo grãos ardidos ao fungicida Azoxistrobina + Benzovindiflupir, e observaram que mesmo em baixas concentrações este fungicida proporcionou considerável redução no crescimento micelial do fungo Aspergillus sp.

Tabela 4. Desdobramento da interação sistema de irrigação $x$ tratamento referente à incidência de fungos do gênero Aspergillus sp. (\%), em grãos de milho envolvendo dois ambientes (com e sem irrigação)

\begin{tabular}{ccccc}
\hline \multirow{2}{*}{ Tratamentos } & \multicolumn{4}{c}{ Sistemas de Irrigação } \\
\cline { 2 - 5 } & \multicolumn{4}{c}{ Híbridos } \\
\cline { 2 - 5 } & BG7051H & BG7060HR & BG7051H & BG7060HR \\
\cline { 2 - 5 } & $34,00 \mathrm{cB}$ & $51,50 \mathrm{cA}$ & $19,00 \mathrm{bA}$ & $13,00 \mathrm{bA}$ \\
\hline Testemunha & $6,00 \mathrm{aA}$ & $27,00 \mathrm{bB}$ & $3,50 \mathrm{aA}$ & $0,00 \mathrm{aA}$ \\
Abacus HC $^{\circ}$ & $25,50 \mathrm{bcA}$ & $18,50 \mathrm{abA}$ & $0,50 \mathrm{aA}$ & $0,00 \mathrm{aA}$ \\
Aproach Prima $^{\circ}$ & $21,50 \mathrm{bA}$ & $10,50 \mathrm{aB}$ & $3,50 \mathrm{aA}$ & $0,00 \mathrm{aA}$ \\
\hline Elatus & $21,75 \mathrm{~A}$ & $26,88 \mathrm{~B}$ & $6,63 \mathrm{~A}$ & $3,25 \mathrm{~A}$ \\
\hline Média Geral & &
\end{tabular}

*Médias seguidas de mesmas letras, minúsculas na coluna e maiúsculas na linha, não diferem estatisticamente entre si pelo Teste de Tukey, em nível de significância de 5\%.

Para o desdobramento dos tratamentos dentro da irrigação, observou-se que tanto no ambiente irrigado quanto no ambiente não irrigado, a massa de mil grãos do tratamento com a aplicação do fungicida Elatus superou o dos demais tratamentos avaliados, com massa de mil grãos de 586,31 g (Tabela 5). Analisando o desdobramento da irrigação dentro dos tratamentos, verificou-se que os tratamentos testemunha, Abacus $\mathrm{HC}^{\circ}$ e Aproach Prima não sofreram influência significativa da irrigação para a variável MMG. Todavia, o Aproach Prima", apresentou MMG significativamente superior no ambiente sem irrigação, com média de 457,54 g, comparando-se o ambiente com irrigação. 
Resultados semelhantes foram descritos por Torres et al. (2013), que ao avaliarem os efeitos do uso da irrigação sobre os componentes de produção na cultura do milho, observaram que o sistema de semeadura convencional e o espaçamento influenciaram na massa de 1000 grãos. Estes resultados podem estar relacionados ao uso da irrigação, que cria um ambiente favorável ao desenvolvimento do patógeno, o que acelera seu desenvolvimento e aumenta sua taxa de crescimento, gerando maiores danos nos grãos e perdas de qualidade e peso, visto que, os conídios dos patógenos saprófitos sobrevivem nos restos culturais ou em sementes por um período de até três anos, sendo disseminados pela água da chuva e também pela irrigação. (VILELA et al., 2012; PILETTI et al., 2014).

Tabela 5. Desdobramento da interação sistema de irrigação x tratamento referente à massa de 1000 grãos (MMG - g), em grãos de milho envolvendo dois ambientes (com e sem irrigação)

\begin{tabular}{cccc}
\hline \multirow{2}{*}{ Tratamentos } & \multicolumn{2}{c}{ Sistemas de Irrigação } & \multirow{2}{*}{ Média Geral } \\
\cline { 2 - 3 } & Com Irrigação & Sem Irrigação & \\
\hline Testemunha $^{\circ}$ & $420,76 \mathrm{bA}$ & $373,29 \mathrm{cA}$ & 397,02 \\
Abacus HC $^{\circ}$ & $399,59 \mathrm{bA}$ & $410,84 \mathrm{bcA}$ & 405,22 \\
Aproach Prima $^{\circ}$ & $389,92 \mathrm{bB}$ & $457,54 \mathrm{bA}$ & 423,73 \\
Elatus $^{\circ}$ & $586,31 \mathrm{aA}$ & $531,95 \mathrm{aA}$ & 559,13 \\
\hline Média Geral & 449,15 & 443,41 & \\
\hline
\end{tabular}

*Médias seguidas de mesmas letras, minúsculas na coluna e maiúsculas na linha, não diferem estatisticamente entre si pelo Teste de Tukey, em nível de significância de $5 \%$.

Analisando o desdobramento da interação irrigação em relação aos híbridos para a produtividade de grãos, verificou-se diferença significativa $(p \leq 0,05)$, o que permite inferir que as plantas dos híbridos de milho apresentaram respostas diferenciadas em relação à irrigação (Tabela 6).

Segundo Ecco et al. (2014), a produtividade da cultura do milho é afetada por inúmeras doenças, dentre elas as principais são as foliares e as relacionadas aos grãos, cujo impacto sobre o rendimento de grãos depende do manejo adotado durante o ciclo da cultura, das condições ambientais, disponibilidade hídrica, fertilidade do solo e do potencial produtivo do híbrido cultivado (CHAVES NETO et al., 2018a,b).

Com base nos resultados para 0 desdobramento dos híbridos em relação à irrigação (com e sem irrigação), observou-se diferença significativa entre os híbridos, onde o híbrido BG7051H apresentou a maior produtividade, com média de $5,48362 \mathrm{Mg} \mathrm{ha}^{-1}$ no ambiente com irrigação. Os híbridos também diferiram no ambiente sem irrigação, onde o híbrido BG7060HR apresentou maior produtividade, com média de 4,22484 $\mathrm{Mg} \mathrm{ha}^{-1}$ (Tabela 6). O híbrido BG7060HR não sofreu influência significativa do ambiente (com e sem irrigação) para a variável produtividade de grãos.
Todavia, o híbrido BG7051H apresentou produtividade significativamente superior no experimento com irrigação, com média de $5,48362 \mathrm{Mg} \mathrm{ha}^{-1}$, quando comparado com ao experimento sem irrigação (Tabela 6). Uma possível explicação é que devido a distribuição da precipitação ao longo do ciclo ou mesmo o uso da irrigação pode influenciar à resistência dos híbridos aos fungos causadores de podridão da espiga e grãos (RIZZARDI et al., 2017).

O comportamento diferenciado dos híbridos quanto aos fungos causadores do complexo grãos ardidos, foram descritos por Piletti et al. (2014), que avaliando a tolerância de 25 híbridos de milho à Stenocarpella macrospora, verificaram comportamento distinto frente aos diferentes isolados, sugerindo diferentes níveis de resistência. Rizzardi, et al. (2017), ao avaliarem o comportamento de diferentes híbridos de milho com e sem inoculação do fungo Stenocarpella maydis, observaram comportamento diferenciado entre os híbridos em relação a incidência de grãos ardidos, que é o dano físico característicos causado pela colonização dos agentes etiológicos das podridões de espigas e grãos na cultura do milho fungos. 
Tabela 6. Desdobramento da interação sistema de irrigação $x$ híbrido referente à produtividade de grãos (PROD - Mg ha ${ }^{-1}$ ), em grãos de milho envolvendo dois ambientes (com e sem irrigação)

\begin{tabular}{cccc}
\hline \multirow{2}{*}{ Híbridos } & \multicolumn{2}{c}{ Sistemas de Irrigação } & \multirow{2}{*}{ Média Geral } \\
\cline { 2 - 3 } & Com Irrigação & Sem Irrigação & \\
\hline BG7051H & $5,48362 \mathrm{aA}$ & $3,10308 \mathrm{bB}$ & 4,29335 \\
BG7060HR & $4,92340 \mathrm{bA}$ & $4,22484 \mathrm{aA}$ & 4,57412 \\
\hline Média Geral & 5,20351 & 3,66396 & \\
\hline
\end{tabular}

*Médias seguidas de mesmas letras, minúsculas na coluna e maiúsculas na linha, não diferem estatisticamente entre si pelo Teste de Tukey, em nível de significância de 5\%.

\section{CONCLUSÕES}

A irrigação favoreceu uma maior incidência de grãos ardidos e dos fungos Fusarium sp. e Aspergillus sp.

O híbrido BG7060HR proporcionou uma menor incidência de fungos e de grãos ardidos, paralelamente a uma maior massa de mil grãos e produtividade quando aplicou-se o fungicida Azoxistrobina + benzovindiflupir.

A aplicação de fungicidas no estádio V8 da cultura reduziu a incidência dos fungos Fusarium sp e Aspergillus sp., destacando-se o fungicida Azoxistrobina + benzovindiflupir.

\section{REFERÊNCIAS}

ABBOTT, W.S. A method of computing the effectiveness of an insecticide. Journal of Economic Entomology, v. 18, p. 265-267, 1925. https://doi.org/10.1093/iee/18.2.265a

ALVES, E.N.T.D.; VERDOLIN, A.L.G.; COSTA, R.V.; COTA, L.V.; SILVA, D.D.; SILVA, O.A. Alternativas de controle para redução de grãos ardidos na cultura do milho. Sete Lagoas-MG: Embrapa Milho e Sorgo, 2012.

BARBOSA, C.A. Manual da Cultura do Milho. AgroJuris: Viçosa, MG. 2010. 199 p.

BIOGENE: Híbridos recomendado para as regiões Centro Alto e Sul: Níveis de tolerância as principais doenças. Disponível em: http://www.biogene.com.br/milho/produtos. Acesso em: 15 nov. 2015.

BRASIL. Ministério da Agricultura e Reforma Agrária. Portaria № 11, de 12 de abril de 1996. Comissão Técnica de Normas e Padrões. Normas de identidade, qualidade, embalagem e apresentação do milho. Brasília, DF. 1996. 13 p.

BRASIL. Ministério da Agricultura, Pecuária e Abastecimento. Regras para análise de sementes. Secretaria de Defesa Agropecuária. Brasília, DF: Mapa/ACS, 2009. 395 p.

BRITO, A.H.; PEREIRA, J.L.A.R.; VON PINHO, R.G.; BALESTRE, M. Controle químico de doenças foliares e grãos ardidos em milho (Zea mays L.). Revista Brasileira de Milho e Sorgo, v.11, n.1, p. 49-59, 2012. https://doi.org/10.18512/19806477/rbms.v11n1p49-59

CHAVES NETO, J.R.; COSTA, I.F.D.; BOSCAINI, R.; LEDUR, N.R.; GUERRA, R.C. Sensibilidade in vitro de fungos isolados de grãos de milho ao fungicida azoxistrobina + benzovindiflupir em diferentes concentrações. Enciclopédia Biosfera, v.13, n.23, $\mathrm{p}$

1211-1224, 2016. https://doi.org/10.18677/Enciclopedia Biosfera 2016106

CHAVES NETO, J.R.; GUERRA, R.C.; BOSCAINI, R.; LEDUR, N.R.; TRAVESSINI, M.; COSTA, I.F.D. Influência do sistema de semeadura e da aplicação de fungicidas sobre a produtividade e qualidade sanitária de milho. Cultura Agronômica, v.27, n.4, p. 573-583, 2018a.

CHAVES NETO, J.R.; GUERRA, R.C.; BOSCAINI, R.; LEDUR, N.R.; TRAVESSINI, M.; COSTA, I.F.D. Desempenho agronômico e qualidade sanitária de grãos de milho, em função da aplicação foliar de fungicidas. Revista Científica Rural, v.20, n.2, p 74-90, 2018b. https://doi.org/10.30945/rcr$\underline{\mathrm{v} 20 \mathrm{i} 2.261}$

CHAVES NETO, J.R.; TRAVESSINI, M.; BOSCAINI, R.; LEDUR, N.R.; COSTA, I.F.D. Eficácia da aplicação foliar de fungicidas no controle de mancha-branca do milho. Revista Tecnologia \& Ciência Agropecuária, v.11, n.1, p. 31-36, 2017.

CONAB. Acompanhamento da safra brasileira de grãos, v. 2 - Safra 2014/15, n. 11 - Décimo primeiro levantamento, agosto de 2015. 
Disponível em: http://www.conab.gov.br. Acesso em: 20 set. 2015.

COSTA, R.V.; COTA, L.V. Controle químico de doenças na cultura do milho: aspectos a serem considerados na tomada de decisão sobre aplicação. Sete Lagoas, 2009. 5 p. (Circular técnica; 214)

COSTA, R.V.; COTA, L.V.; SILVA, D.D.; MEIRELLES, W.F.; LANZA, F.E. Viabilidade técnica e econômica da aplicação de estrobilurinas em milho. Tropical Plant Pathology, v.37, n.4, p. 246-254, 2012. https://doi.org/10.1590/S1982-

$\underline{56762012000400003}$

COSTA, R.V.; SILVA, D.D.; COTA, L.V. Reação de cultivares de milho à ferrugem polissora em casa de vegetação. Sete Lagoas, 2015. 11 p. (Circular técnica; 125)

CRUZ, J.C.; PEREIRA FILHO, I.A.; QUEIROZ, L.R. Quatrocentas e sessenta e sete cultivares de milho estão disponíveis no mercado de sementes do Brasil para a safra 2013/14. Sete Lagoas: Embrapa, 2013. Disponível em: http://www.cnpms.embrapa.br/milho/cultivares. Acesso em: 14 maio 2017.

DUARTE, R.P.; JULIATTI. F.C.; FREITAS, P.T. Eficácia de diferentes fungicidas na cultura do milho. Bioscience Journal, v.25, n.4, p. 101-111, 2009.

ECCO, M.; ROSSET, J.S.; RAMPIM, L.; COSTA, A.C.T.; LANA, M.C.; STANGARLIN, J.R.; SARTO, M.V.M. Características agronômicas de híbridos de milho segunda safra submetidos à aplicação de fungicida. Revista Agrarian, v.7, n.26, p. 504510, 2014.

EMBRAPA. Sistema Brasileiro de Classificação do Solo - SIBCS. 3. ed. Brasília: Centro Nacional de Pesquisa de Solos, 2013a. 306 p.

EMBRAPA. Reunião técnica anual de milho. Indicações técnicas para o cultivo de milho e de sorgo no Rio Grande do Sul safras 2013/2014 e 2014/2015. Brasília, 2013b. 124 p.

FERREIRA, D.F. Sisvar: A Guide for its Bootstrap procedures in multiple comparisons. Ciência \& Agrotecnologia, v.38, n.2, p.109-112, 2014. http://dx.doi.org/10.1590/\$14137054201400020 0001

GARCÉS-FIALLOS, F.R.; FORCELINI, C.A. Controle comparativo da ferrugem asiática da soja com fungicida triazol ou mistura de triazol + estrobilurina. Bioscience Journal, v.29, n.4, p. 805-815, 2013.

GONÇALVES, M.E.M.P.; GONÇALVES JUNIOR, D.; SILVA, A.G.; CAMPOS, H.D.; SIMON, G.A.; SANTOS, C.J.L.; SOUSA, M.A. Viabilidade do controle químico de doenças foliares em híbridos de milho no plantio de safrinha. Nucleus, v.9, n.1, p.49-62, 2012. https://doi.org/10.3738/1982.2278.630

JULIATTI, F.C.; BELOTI, I.F.; JULIATTI, B.C. M.; CRATO, F.F. Eficácia da associação de fungicidas e antibióticos no manejo da mancha branca do milho e seu efeito na produtividade. Bioscience Journal, v.30, n.6, p. 1622-1630, 2014.

KLUGE, E.R.; MENDES, M.C.; FARIA, M.V.; SANTOS, L.A.; SANTOS, E.O.; SZEUCZUK, K. Effect of foliar fungicide and plant spacing on the expression of lipoxygenase enzyme and grain rot in maize hybrids. Acta Scientiarum. Agronomy, v.39, n.4, p.407-415, 2017. https://doi.org/10.4025/actasciagron.v39i4.3300 $\underline{3}$

KÖPPEN, W. Climatologia. México: Fundo de Cultura Económica, 1948.

LANZA, F.E.; ZAMBOLIM, L.; COSTA, R.V.; SILVA, D.D.; QUEIROZ, V.A.V.; PARREIRA, D.F.; MENDES, S.M.; SOUZA, A.G.C.; COTA, L.V. Aplicação foliar de fungicidas e incidência de grãos ardidos e fumonisinas totais em milho. Pesquisa Agropecuária Brasileira, v.51, n.5, p. 638-646, $2016 . \quad$ https://doi.org/10.1590/S0100$204 \times 2016000500026$

LOPES, L.N.S.; SILVA, A.S.; PEREIRA, C.C.O.; MENEZES, I.P.P.; MALAFAIA, G.; LIMA, M.L.P. Sensibilidade de isolados de Colletotrichum gloeosporioides a fungicidas. Multi-Science Journal, v.1, n.1, p. 106-114, 2015.

MANERBA, F.C.; SOUZA, P.E.; PINHO, R.G.V.; DORNELAS, G.A.; MONTEIRO, F.P. Antibióticos no Controle da Mancha Branca do Milho. Comunicata Scientiae, v.4, n.4, p. 361-367, 2013. 
MENDES, M.C.; PINHO, R.G.V.; MACHADO, J.C.; ALBUQUERQUE, C.J.B.; FALQUETE, J.C.F. Qualidade sanitária de grãos de milho com e sem inoculação a campo dos fungos causadores de podridões de espiga. Ciência e Agrotecnologia, v.35, n.5, p. 931-939, 2011. https://doi.org/10.1590/S1413-

$\underline{70542011000500010}$

MENDES, M.C.; PINHO, R.G.V.; PINHO, E.V.R.V.; FARIA, M.V. Comportamento de híbridos de milho inoculados com os fungos causadores do complexo grãos ardidos e associação com parâmetros químicos e bioquímicos. Ambiência Revista do Setor de Ciências Agrárias e Ambientais, v.8, n.2, p. 275-292, 2012.

MUNHOZ, A.T.; CARVALHO, R.V.; QUERALES, P.J.; GONÇALVES, F.P.; CAMARGO, L.E.A. Relação entre resistência de linhagens tropicais de milho à podridão de espiga e ao acúmulo de fumonisinas provocados por Fusarium verticillioides. Summa Phytopathologica, v.41, n.2, p.144-148, 2015. https://doi.org/10.1590/0100-5405/1962

PILETTI, G.J.; CASA, R.T.; BAMPI, D.; PILETTI, L.M.M.S.; STOLTZ, J.C.; SANGOI, L.; MICHELUTTI, D. Reação de híbridos de milho à mancha-demascropora. Summa Phytopathologica, v.40, n.1, p.24-28, 2014. https://doi.org/10.1590/S0100$\underline{54052014000100003}$

PINTO, N.F.J.A. Grãos ardidos em milho. Sete Lagoas: Embrapa Milho e Sorgo, 2005. 6 p. (Circular técnica; 66)

RIZZARDI, D.A.; FARIA, C.M.D.R.; FARIA, M.V.; MENDES, M.C.; ROSSI, E.S.; FIGUEIREDO, A.S.T.; POSSATO JÚNIOR, O. Artificial com Stenocarpella maydis em híbridos de milho. Scientia Agraria Paranaensis, v.16, n.2, p. 166-170, 2017.

SABATO, E.O.; PINTO, N.F.J.A.; FERNANDES, F.T. Identificação e controle de doenças na cultura do milho. 2. ed. Brasília: Embrapa, 2013. 198 p.

SILVA, A.G.; TEIXEIRA, I.R.; MARTINS, P.D.S.; SIMON, G.A.; FRANCISCHINI, R. Desempenho agronômico e econômico de híbridos de milho na safrinha. Revista Agroambiente, v. 8, n. 2, p. 261$271, \quad 2014 . \quad$ https://doi.org/10.18227/19828470ragro.v8i2.1706
SMALL, I.M.; FLETT, B.C.; MARASAS, W.F.O.; MCLEOD, A.; VILOEN, A. Use of resistance elicitors to reduce Fusarium ear rot and fumonisin accumulation in maize. Crop Protection, v.41, p. 10-16, 2012. https://doi.org/10.1016/i.cropro.2012.05.016

STEFANELLO, J.; BACHI, L.M.A.; GAVASSONI, W.L.; HIRATA, L.M.; PONTIM, B.C.A. Incidência de fungos em grãos de milho em função de diferentes épocas de aplicação foliar de fungicida. Pesquisa Agropecuária Tropical, v.42, n.4, p. 476481, 2012. https://doi.org/10.1590/S198340632012000400014

STUMPF, R.; SANTOS, J.; GOMES, L.B.; SILVA, C.N.; TESSMANN, D.J.; FERREIRA, F.D.; MACHINSKI JUMIOR, M.; DEL PONTE, E.M. Fusarium species and fumonisins associated with maize kernels produced in Rio Grande do Sul State for the 2008/09 and 2009/10 growing seasons. Brazilian Journal of Microbiology, v.44, n.1, p. 89-95, $2013 . \quad$ https://doi.org/10.1590/S1517$\underline{83822013000100012}$

TORRES, F.E. LANGHI, G.; TEODORO, P.E.; RIBEIRO, L.P.; CORRÊA, C.C.G.; OLIVEIRA, E.P. Desempenho de híbridos de milho cultivados em diferentes espaçamentos na região do cerrado brasileiro. Revista de Ciências Agrárias, v.36, n.4, p. 411-416, 2013.

VILELA, R.G.; ARF, O.; KAPPES, C.; KANEKO F.H.; GITTI, D.C.; FERREIRA, J.P. Desempenho agronômico de híbridos de milho, em função da aplicação foliar de fungicidas. Bioscience Journal, v.28, n.1, p. 25-33, 2012.

Recebido para publicação em 05/07/2018

Revisado em 17/01/2019

Aceito em 18/01/2019 